\title{
Evaluation of exercise electrocardiography and thallium tomographic imaging in detecting asymptomatic coronary artery disease in diabetic patients
}

\author{
M Juhani Koistinen, Heikki V Huikuri, Heikki Pirttiaho, Markku K Linnaluoto, \\ Juha T Takkunen
}

\begin{abstract}
Thallium tomographic imaging and exercise electrocardiography were performed on 136 diabetic patients without symptoms of heart disease. Thirty three patients had post-exercise thallium defects and 19 had ST $1 \mathrm{~mm} \geqslant$ segment depression during exercise electrocardiography. Both tests were positive in 13 patients. Coronary angiography was subsequently performed on 33 patients with either scintigraphic and/or electrocardiographic evidence of myocardial ischaemia. Angiographically significant coronary artery disease $(\geqslant 50 \%$ narrowing of the coronary artery lumen) was detected in 13 patients. Six patients had minimal coronary artery stenosis $(<50 \%)$, and 14 had normal coronary arteries. Six patients refused cardiac catheterisation. In 14 out of 27 patients with post-exercise thallium defects coronary angiography did not show any coronary artery stenoses (positive predictive accuracy $\mathbf{4 8} \%$ ). Exercise electrocardiography showed only one false positive result (positive predictive accuracy 94\%) but failed to detect coronary artery disease in three patients with a positive scintigraphic result.

The accuracy of a positive exercise electrocardiographic test seems to be better than that of a positive thallium tomographic scan for detecting asymptomatic coronary artery disease in diabetic patients. The high number of false positive thallium defects may be the result of technical features inherent in thallium tomography and/or the possible disease of the small intramyocardial arteries in diabetic patients.
\end{abstract}

Heart disease is a major cause of mortality and morbidity in diabetic patients ${ }^{1}$ and coronary artery disease is more common in diabetic patients. ${ }^{2}$ Silent myocardial infarctions are common and myocardial ischaemic episodes often tend to be asymptomatic in diabetic patients. ${ }^{3-5}$ Recent studies suggest that silent myocardial ischaemia may be accompanied by increased mortality, ${ }^{67}$ and hence non-invasive tests have been recommended to detect asymptomatic coronary artery disease. We evaluated the usefulness of thallium tomographic imaging and exercise electrocardiography for detecting coronary artery disease in a population of diabetic patients without symptoms of heart disease.

\section{Patients and methods}

PATIENTS

The diabetic patients were selected from the patient register of Oulu University Central Hospital and the membership register of the local diabetic association. Table 1 presents their clinical data. Those classified as having type I diabetes (insulin dependent diabetes mellitus, $n=70$ ) had had diabetes and a tendency to ketosis from an early age, while those classified as type II diabetic patients (noninsulin dependent diabetes mellitus, $n=66$ ) were treated with a diet alone or with a diet combined with oral hypoglycaemic agents. Patients with type II diabetes were not liable to ketosis and showed considerable C-peptide activity after glucagon stimulation. All the diabetic patients fulfilled the World Health Organisation criteria for idiopathic diabetes mellitus. We studied 50 women and 86 men.

The exclusion criteria were: $(a)$ age $<35$ or $>60$; $(b)$ duration of type I diabetes $<5$ years; (c) known ischaemic heart disease; (d) symptoms of ischaemic heart disease according to the Rose questionnaire; (e) antilipidaemic medication; $(f)$ severe renal disease (serum creatinine $>200 \mathrm{mmol} / \mathrm{l}$ ); (g) uncontrolled retinopathy; $(h)$ thyroid disease, overt malignant tumours, alcoholism; and ( $i$ ) any severe disease that could be contraindication for the maximal exercise test.

All the patients gave their informed consent and the investigation was approved by the ethics committee of the Faculty of Medicine at the University of Oulu.

\section{METHODS}

Eligible patients were examined by maximal exercise electrocardiography and exercise thallium tomographic imaging. If either of these non-invasive tests showed signs of myocardial ischaemia the patient was recalled for cardiac catheterisation. 
Table 1 Clinical characteristics of the diabetic patients (mean (SD))

\begin{tabular}{|c|c|c|c|}
\hline & $\begin{array}{l}I D D M \\
(n=70)\end{array}$ & $\begin{array}{l}\text { NIDDM } \\
(n=66)\end{array}$ & $\begin{array}{l}\text { Both } \\
(n=136)\end{array}$ \\
\hline $\begin{array}{l}\text { Age }(y r) \\
\text { Sex }(F / M) \\
\text { Duration of diabetes }(y r) \\
\text { Treatment of diabetes: }\end{array}$ & $\begin{array}{l}46 \cdot 3(7 \cdot 3) \\
31 / 39 \\
13(8)\end{array}$ & $\begin{array}{l}49 \cdot 4(6 \cdot 8) \\
19 / 47 \\
10(6)\end{array}$ & $\begin{array}{l}47 \cdot 8(7 \cdot 2) \\
50 / 86 \\
12(7)\end{array}$ \\
\hline $\begin{array}{l}\text { Insulin } \\
\text { Insulin and oral hypoglycaemic agents } \\
\text { Oral hypoglycaemic agents } \\
\text { Diet only }\end{array}$ & $\begin{array}{c}69(99 \%) \\
1(1 \%)\end{array}$ & $\begin{array}{l}15(23 \%) \\
1(2 \%) \\
26(39 \%) \\
24(36 \%)\end{array}$ & $\begin{array}{l}84(62 \%) \\
2(1 \%) \\
26(19 \%) \\
24(18 \%)\end{array}$ \\
\hline $\begin{array}{l}\text { Glycated haemoglobin } A_{1}(\%) \\
\text { Blood glucose }(\mathrm{mmol} / \mathrm{l}) \\
\text { Serum cholesterol (mmol/l) }\end{array}$ & $\begin{array}{r}11.4(2.3) \\
11.0(3.7) \\
5.8(1.0)\end{array}$ & $\begin{array}{r}11.0(2.7) \\
10.7(3.9) \\
5.9(1.2)\end{array}$ & $\begin{array}{r}11.3(2.5) \\
10.9(3.8) \\
5.8(1.1)\end{array}$ \\
\hline
\end{tabular}

IDDM, insulin dependent diabetes mellitus; NIDDM, non-insulin dependent diabetes mellitus. terolateral-were defined. Regional perfusion was regarded as abnormal if a defect could be seen in at least two tomographic sections with or without redistribution. The thallium defects were graded as mild, moderate, or severe by visual interpretation of the images. Complete agreement between the observers about the presence or absence of coronary artery disease was achieved in 125 (92\%) cases and a consensus was obtained by discussion in the remaining $11(8 \%)$ cases.

\section{Cardiac catheterisation}

All the patients who showed signs of myocardial ischaemia in the above non-invasive tests were recalled for cardiac catheterisation. Six of the 39 refused to undergo this procedure. The remaining 33 patients underwent left sided cardiac catheterisation, including selective coronary arteriography in multiple projections comprising caudal and cranial views obtained by the Judkins technique. Biplanar left ventricular cineangiograms were taken as described earlier..$^{9}$ A reduction of $\geqslant 50 \%$ of luminal diameter was regarded as a significant lesion. The angiographic findings were interpreted by two experienced observers.

\section{Results}

EXERCISE ELECTROCARDIOGRAPHY AND SCINTIGRAPHY DATA

One hundred and three patients $(76 \%)$ reached $85 \%$ of the maximum heart rate predicted for their age during the bicycle exercise test while the remaining $33(24 \%)$ stopped because of fatigue without reaching this maximum. None of the patients had angina or chest pain during the stress test. Nineteen patients $(14 \%)$ had $\geqslant 1 \mathrm{~mm} \mathrm{ST}$ depression during or after exercise and $117(86 \%)$ had a normal electrocardiographic response to exercise. Thirty three patients $(24 \%)$ had defects in the post-exercise thallium tomographic images, these being reversible in 23 (16 mild, five moderate, two severe), fixed in eight (six mild, one moderate, one severe), and diffuse reductions of thallium uptake in two. Figure 1 shows an example of thallium tomographic images from a symptom free patient with three vessel disease in coronary angiography. The haemodynamic responses were similar in patients during exercise electrocardiography and thallium scintigraphy (table 2).

\section{RELATION BETWEEN CORONARY ANGIOGRAPHY} FINDINGS AND RESULTS OF THE NON-INVASIVE TESTS

Thirteen patients had coronary artery stenosis ( $\geqslant 50 \%$ narrowing), six had coronary artery narrowings of $<50 \%$, and 14 had angiographically normal coronary arteries. Three patients had three vessel disease, five patients had two vessel disease, and five patients had one vessel disease. Table 3 shows the relations between the angiographic findings and the results of non-invasive tests. Fourteen of 27 patients with positive scintigraphic results had normal findings at coronary angiography (positive predictive accuracy $48 \%$ ), while only one of 17 patients with positive exercise
The images for each patient were examined by two different observers without knowledge of the angiographic information. Five discrete regions of the left ventricular myocardiumanterior, septal, apical, inferior and pos- 


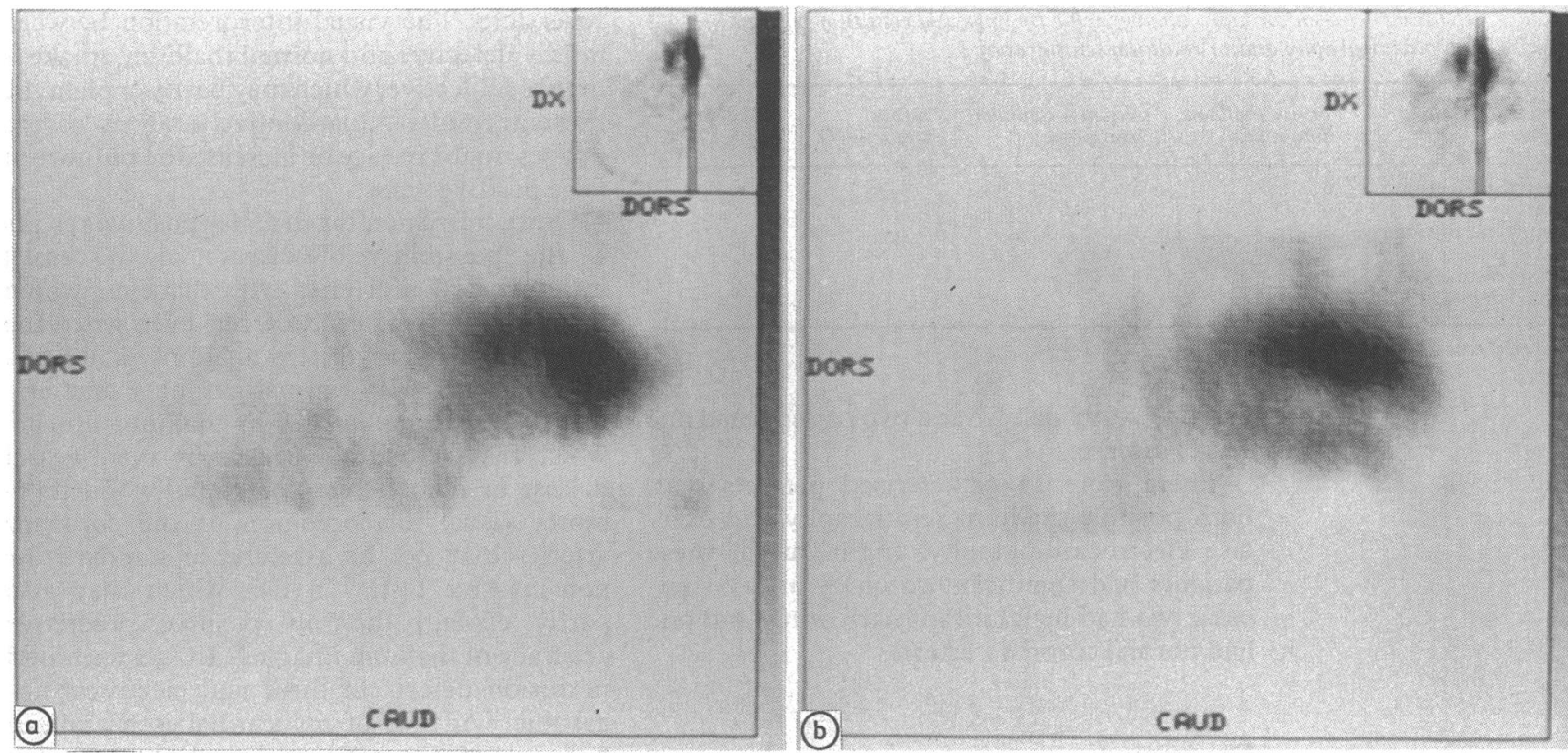

Figure 1 An example of thallium tomographic images in a symtom free patient with three vessel disease detected by coronary angiography. There were reversible defects in the inferoposterior and apical regions of the left ventricle. Sagittal sections (a) at rest and (b) after dynamic exercise.

electrocardiography had normal coronary angiography (positive predictive accuracy $94 \%)$.

Nine (eight mild, one moderate) out of 14 false positive defects were reversible and five (mild) defects were fixed. Five (mild) out of the 14 false positive defects were in the anterior region, four (three mild, one moderate) in the inferior region, two (mild) in the septal region, one (mild) in the posterior region of the left ventricle, and two defects were diffuse reductions of thallium uptake. Figure 2 shows a false positive thallium scan.
There were two patients with a positive thallium scan and negative exercise electrocardiography who had significant coronary artery stenoses and one who had insignificant stenoses. Conversely there were three patients with positive exercise electrocardiography and negative thallium scan who had significant coronary artery stenoses and three patients who had insignificant coronary artery stenoses. One patient with a false negative exercise electrocardiogram had two vessel coronary artery disease and the other had one vessel disease, whereas one patient with negative thallium scintigraphy

Table 2 Haemodynamic data during exercise electrocardiography and thallium scintigraphy in the catheterised patients

\begin{tabular}{|c|c|c|c|c|c|c|c|c|c|c|}
\hline \multirow[b]{3}{*}{ Case no } & \multicolumn{4}{|c|}{ Exercise electrocardiography } & \multirow{3}{*}{$\begin{array}{l}\operatorname{Load}(\max ) \\
(\mathbb{W})\end{array}$} & \multicolumn{4}{|c|}{ Thallium scintigraphy } & \multirow{3}{*}{$\begin{array}{l}\operatorname{Load}(\max ) \\
(W)\end{array}$} \\
\hline & \multicolumn{2}{|c|}{ Heart rate (beats/min) } & \multicolumn{2}{|c|}{$S B P\left(m m H_{g}\right)$} & & \multicolumn{2}{|c|}{ Heart rate (beats/min) } & \multicolumn{2}{|c|}{$S B P\left(m m H_{g}\right)$} & \\
\hline & Rest & Exercise & Rest & Exercise & & Rest & Exercise & Rest & Exercise & \\
\hline $\begin{array}{r}1 \\
2 \\
3 \\
4 \\
5 \\
6 \\
7 \\
8 \\
9 \\
10 \\
11 \\
12 \\
13 \\
14 \\
15 \\
16 \\
17 \\
18 \\
19 \\
20 \\
21 \\
22 \\
23 \\
24 \\
25 \\
26 \\
27 \\
28 \\
29 \\
30 \\
31 \\
32 \\
33\end{array}$ & $\begin{array}{l}078 \\
069 \\
115 \\
095 \\
076 \\
067 \\
076 \\
100 \\
075 \\
110 \\
053 \\
071 \\
063 \\
078 \\
063 \\
085 \\
072 \\
069 \\
090 \\
057 \\
085 \\
064 \\
090 \\
080 \\
072 \\
085 \\
091 \\
065 \\
081 \\
066 \\
084\end{array}$ & $\begin{array}{l}165 \\
131 \\
178 \\
155 \\
160 \\
153 \\
171 \\
172 \\
165 \\
178 \\
156 \\
171 \\
154 \\
150 \\
150 \\
123 \\
145 \\
170 \\
166 \\
170 \\
170 \\
112 \\
153 \\
155 \\
150 \\
133 \\
106 \\
160 \\
153 \\
182 \\
168 \\
163 \\
173\end{array}$ & $\begin{array}{l}140 \\
145 \\
130 \\
195 \\
105 \\
130 \\
130 \\
180 \\
150 \\
170 \\
145 \\
145 \\
160 \\
150 \\
135 \\
170 \\
120 \\
130 \\
130 \\
180 \\
140 \\
155 \\
155 \\
155 \\
130 \\
140 \\
130 \\
165 \\
160 \\
110 \\
125 \\
145 \\
130\end{array}$ & $\begin{array}{l}200 \\
180 \\
210 \\
270 \\
180 \\
210 \\
230 \\
240 \\
220 \\
185 \\
190 \\
240 \\
210 \\
215 \\
230 \\
190 \\
180 \\
220 \\
210 \\
240 \\
210 \\
125 \\
200 \\
210 \\
210 \\
240 \\
170 \\
240 \\
200 \\
175 \\
180 \\
240 \\
185\end{array}$ & $\begin{array}{l}090 \\
120 \\
180 \\
195 \\
090 \\
210 \\
120 \\
180 \\
210 \\
070 \\
165 \\
255 \\
195 \\
225 \\
225 \\
070 \\
180 \\
255 \\
100 \\
240 \\
195 \\
120 \\
120 \\
165 \\
120 \\
135 \\
130 \\
120 \\
180 \\
195 \\
210 \\
180 \\
210\end{array}$ & $\begin{array}{l}083 \\
135 \\
095 \\
100 \\
090 \\
080 \\
080 \\
090 \\
073 \\
125 \\
074 \\
080 \\
055 \\
074 \\
064 \\
096 \\
087 \\
070 \\
090 \\
066 \\
100 \\
059 \\
088 \\
070 \\
085 \\
081 \\
098 \\
095 \\
082 \\
095 \\
079 \\
100 \\
064\end{array}$ & $\begin{array}{l}155 \\
165 \\
160 \\
150 \\
160 \\
160 \\
170 \\
129 \\
145 \\
175 \\
125 \\
165 \\
155 \\
136 \\
142 \\
130 \\
150 \\
152 \\
162 \\
165 \\
160 \\
108 \\
155 \\
140 \\
142 \\
125 \\
160 \\
168 \\
130 \\
180 \\
158 \\
138 \\
150\end{array}$ & $\begin{array}{l}170 \\
110 \\
120 \\
180 \\
125 \\
105 \\
160 \\
150 \\
110 \\
185 \\
125 \\
120 \\
145 \\
150 \\
100 \\
130 \\
150 \\
120 \\
155 \\
150 \\
140 \\
155 \\
120 \\
110 \\
130 \\
160 \\
120 \\
140 \\
160 \\
110 \\
120 \\
150 \\
140\end{array}$ & $\begin{array}{l}195 \\
160 \\
230 \\
260 \\
150 \\
190 \\
210 \\
220 \\
220 \\
220 \\
210 \\
210 \\
170 \\
220 \\
185 \\
200 \\
200 \\
210 \\
190 \\
230 \\
190 \\
145 \\
170 \\
230 \\
185 \\
210 \\
170 \\
230 \\
190 \\
175 \\
190 \\
260 \\
210\end{array}$ & $\begin{array}{l}090 \\
110 \\
195 \\
180 \\
090 \\
210 \\
130 \\
135 \\
195 \\
080 \\
150 \\
240 \\
195 \\
195 \\
225 \\
120 \\
195 \\
255 \\
100 \\
240 \\
225 \\
120 \\
150 \\
180 \\
120 \\
135 \\
140 \\
120 \\
180 \\
195 \\
210 \\
120 \\
135\end{array}$ \\
\hline
\end{tabular}


Table 3 Relation between coronary angiographic findings and results of positive exercise electrocardiography and/or thallium scintigraphy

\begin{tabular}{lllll}
\hline $\begin{array}{l}\text { Diseased coronary } \\
\text { arteries }\end{array}$ & $\begin{array}{l}\text { Positive thallium } \\
\text { scintigraphy }\end{array}$ & $\begin{array}{l}\text { Negative thallium } \\
\text { scintigraphy }\end{array}$ & $\begin{array}{l}\text { Positive } \\
\text { exercise ECG }\end{array}$ & $\begin{array}{l}\text { Negative } \\
\text { exercise ECG }\end{array}$ \\
\hline Refused angiography & 6 & 0 & 2 & 4 \\
None & 14 & 0 & 1 & 13 \\
Minimal narrowings & 3 & 3 & 5 & 1 \\
1 vessel disease & 3 & 2 & 4 & 1 \\
2 vessel disease & 4 & 1 & 4 & 1 \\
3 vessel disease & 3 & 0 & 3 & 0 \\
\hline
\end{tabular}

ECG, electrocardiogram.

had two vessel disease and two patients had one vessel disease.

There were 11 catheterised patients with both positive thallium scintigraphy and exercise electrocardiography. Eight out of these patients had significant coronary artery stenoses, two had insignificant narrowing, and one had normal coronary arteries.

\section{Discussion}

Thallium tomographic imaging showed perfusion defects in a high proportion of diabetic patients without symptoms of heart disease. These results are consistent with a previous survey in which $42 \%$ of symptom free diabetic men had positive thallium scans, ${ }^{10}$ although this study did not relate the thallium results to coronary angiographic findings.

In the present study, thallium tomographic imaging showed perfusion defects in $24 \%$ of patients. Perfusion defects were commonly detected when coronary angiography showed a normal epicardial coronary artery anatomy. Some of the false positive thallium scintigraphic results may be the result of technical features inherent in thallium tomography, such as breast artefacts, inaccurate patient positioning between imaging phases, diaphragmatic attentuation of the inferior cardiac wall, abnormal apical thinning, computer processing errors, or obesity. ${ }^{11}$ Thallium defects in the false positive scans were usually mild and reversible. The visual interpretation between mildly defective and normal thallium uptake is highly subjective, which may partly explain the present results. Quantitative analysis of the images might reduce or increase the number of false positive scans.

One explanation for the false positive results is the possibility of disease of the small intramyocardial arteries with diabetes, which may result in perfusion defects even when the epicardial coronary artery anatomy is normal. Two patients with normal coronary anatomy had diffuse irregularities in thallium uptake, which may actually be caused by small vessel disease or diabetic cardiomyopathy. Furthermore, visual interpretation of the coronary arteries may not be a reference standard for non-invasive tests, ${ }^{12}$ a fact which may also partly explain the low positive predictive accuracy of thallium imaging. In fact we found perfusion defects in three and electrocardiographic evidence of myocardial ischaemia in five out of six patients in whom coronary narrowings was interpreted as minimal $(<50 \%)$. We know of no other evaluations of the positive preditive accuracy of single photon emission computed tomography in a large series of symptom free patients. When we used the imaging method described, we found a high sensitivity and specificity of thallium tomographic method in different patient populations. $^{813}$ The present data further emphasise the need for validating the new noninvasive tests in patient populations with different pre-test probabilities of myocardial ischaemia. ${ }^{14}$

An abnormal exercise electrocardiogram is more common in diabetic than in non-diabetic patients. The prevalence of abnormal ST segment changes has been estimated to be $20-23 \%$ in symptom free diabetic populations ${ }^{41516}$ and $2-13 \%$ in other symptom free populations. ${ }^{17}$ The prevalence of abnormal exercise electrocardiography was $14 \%$ in this study. The predictive accuracy for abnormal exercise elec-

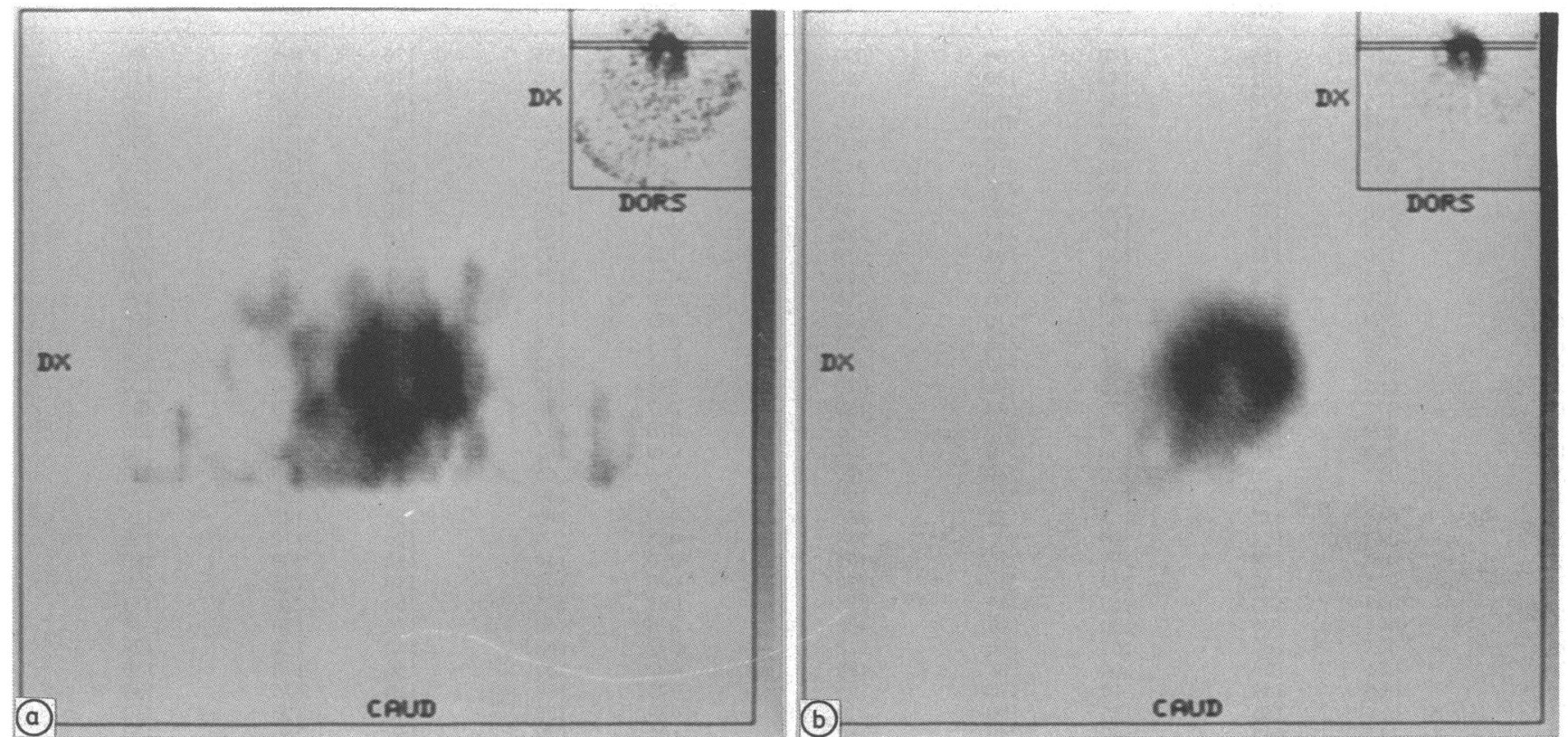

Figure 2 An example of a false positive thallium scan in a patient with normal coronary angiography. A reversible defect in the inferoposterior region of the left ventricle. Coronal sections $(a)$ at rest and $(b)$ after dynamic exercise. 
trocardiography in symptom free cohorts has been reported to be only $20 \%{ }^{18}$ On the contrary, the positive predictive accuracy of exercise electrocardiography was as high as $94 \%$ in the present series. According to Bayes' theorem the predictive value varies with the prevalence of disease. ${ }^{19}$ We studied mostly male, middle aged and elderly diabetic patients. In this type of population the prevalence of coronary artery disease is high, perhaps explaining the high predictive accuracy of exercise electrocardiography in the present study.

The predictive accuracy of exercise electrocardiography was better than that of thallium imaging but it still failed to detect three patients with coronary artery disease. These results accord with previous observations that exercise electrocardiography may have a low sensitivity for detecting coronary artery disease. ${ }^{2021}$ In the present study we could not calculate the absolute sensitivity and specificity of these methods, because this would have required all the patients to be catheterised.

Screening of certain high risk populations has recently been proposed for detecting coronary artery disease, because of the possibility of silent myocardial ischaemia. ${ }^{182223}$ The present findings suggest that thallium tomographic imaging may not be a particularly useful non-invasive screening method in symptom free diabetic patients because of its low positive predictive accuracy. The accuracy of a positive exercise electrocardiogram is higher, but it may have lower sensitivity.

This study was supported by a grant from the Finnish Foundation for Cardiovascular Research and Ida Montin's Foundation, Helsinki, Finland.

1 Palumbo PJ, Elveback LR, Chu CP, Connolly DC, Kurland LT. Diabetes mellitus: incidence, prevalence, survivorship, and causes of death in Rochester, Minnesota, 194570. Diabetes 1976;25:566-73.

2 Jarret RJ. The epidemiology of coronary heart disease and related factors in the context of diabetes mellitus and impaired glucose tolerance. In: Jarret, ed. Diabetes and heart disease. Amsterdam: Elsevier Science Publishers heart disease.
3 Bradley RF, Sconfeld A. Diminished pain in diabetic patients with acute myocardial infarction. Geriatric 1962;17:322-6.

4 Bellet S, Roman L. The exercise test in diabetic patients as studied by radioelectrocardiography. Circulation 1967 36:245-54.

5 Chiariello M, Indolfi C, Cotecchia MR, Sifola C, Romano M, Condererlli M. Asymptomatic transient ST changes during ambulatory ECG monitoring in diabetic patients. Am Heart J 1985;110:529-34.

6 Cohn PF. Detection and prognosis of asymptomatic patient with silent myocardial ischemia. Am $J$ Cardiol 1988;61:4B-6B.

7 Hickman JR, Uhl GS, Cook RL, Engel PH, Hoprik A. A natural history study of asymptomatic coronary disease natural history study of asymptomatic
[Abstract]. Am J Cardiol 1980;45:422.

8 Huikuri HV, Korhonen UR, Airaksinen KEJ, Ikäheimo MJ Heikkilä J, Takkunen JT. Comparison of dipyridamolehangrip test and bicycle exercise for thallium tomographic hangrip test and bicycle exercise for tha

9 Huikuri HV, Ikäheimo MJ, Linnaluoto MMK, Takkunen JT. Left ventricular response to isometric exercise and its value in predicting the change in ventricular function afte mitral valve replacement for mitral regurgitation. $A m J$ Cardiol 1983;51:1110-5.

10 Abenavoli T, Rubler S, Fisher VJ, Axelrod HI, Zuckerman $\mathrm{KP}$. Exercise testing with myocardial scintigraphy in asymptomatic diabetic males. Circulation 1981;63:54-64.

11 Berman DS, Rozanksi A, Knoebel SB. The detection of silent ischemia: cautions and precautions. Circulation 1987;75:101-5.

12 Marcus ML, Skorton DJ, Johnson MR, Collins SM, Harrison DG, Kerber RE. Visual estimates of percent diameter coronary stenosis: "a battered gold standard". J Am Coll Cardiol 1988;11:882-5.

13 Huikuri HV, Airaksinen KEJ, Ikäheimo MJ, Korhonen UR Heikkilä J, Takkunen JT. Detection of coronary artery disease by dipyridamole thallium tomography in mitral disease by dipyridamole thallium tomography
valve stenosis. Am J Cardiol 1989;63:124-6.

14 Ransohoff DF, Feinstein AR. Problems of spectrum and bias in evaluating the efficacy of diagnostic tests. $N$ Engl $J$ bias in evaluating the effic

15 Levitas IM, Kristal JJ. Stress exercise testing of the young diabetic for detection of unknown coronary artery disease. Isr J Med Sci

16 Storstein L, Jervell J. Response to bicycle exercise testing in long-standing juvenile diabetic. Acta Med Scand 1979;205:227-30

17 Faris JV. Exercise testing: screening and reproducibility in asymptomatic subjects. Cardiol Clin 1984;2(3):415-28.

18 Doyle JT. Epidemiologic aspects of the asymptomatic positive exercise test. Circulation 1987;75(suppl II):12-3

19 Beller GA, Gibson RS. Sensitivity, specificity and prognostic significance of non-invasive testing for occult or known coronary disease. Prog Cardiovasc Dis 1987;23(4):241-70.

20 Fortuin NJ, Weiss JL. Exercise stress testing. In: Weissler AM, ed. Reviews of contemporary laboratory methods. Dallas: American Heart Association, 1980;157-95.

21 Goldschlager $\mathbf{N}$. Use of treadmill test in the diagnosis of coronary artery disease in patients with chest pain. Ann coronary artery disease in
Intern Med 1982;97:383-8.

22 Froelicher VF, Thompson AJ, Longo MR Jr, Triebwasser $\mathrm{JH}, \mathrm{Lancaster} \mathrm{MC}$. Value of exercise testing for screening asymptomatic men for latent coronary artery disease. Prog asymptomatic men for latent coro
Cardiovasc Dis $1976 ; 18: 265-76$.

23 Cohn PF. Silent myocardial ischemia: classification prevalence, and prognosis. Am J Med 1985;79(suppl 3 A) $: 2-6$. 